\title{
DEFINING THE INFLUENCE OF THE SUPPORT OF BUS SERVICE ON ROAD SAFETY
}

The paper deals with the relationship of increasing road safety through the support of bus service. The objective of the paper is to analyse the factors affecting road safety. Subsequently, the impact of the bus service support on road safety is expressed through those factors. The paper highlights the multiplier effect of the bus service support on road safety increase. First part of the paper analyses factors affecting road safety. The factors are divided into three groups in terms of infrastructure, vehicles and drivers. Further part emphasizes the possibilities for improving individual factors under the support of bus service. The last part of the paper processes a theoretical model which reflects the impact of the bus service support on increasing road safety.

Keywords: Transport, accidents, safety, driver, vehicle, infrastructure.

\section{Introduction}

Road safety represents an all-society problem not only in the EU but also in non-member states of the EU [1]. The number of persons killed per 100000 population represents a value higher than 2 persons per year depending on the EU member state [2]. Many authors agree, e.g. Koorntra et al. [3] or Subramanian [4], the safety of road transport is improving because of the decrease of the share of killed persons in road traffic. However, the number of traffic accidents and particularly the number of fatalities is significantly higher than the aim specified in strategic documents of the EU [5].

So far, all measures aimed at increasing road safety have been focused on infrastructure, vehicles and drivers. Road safety in relation to infrastructure was increased through increasing capacity of infrastructure. However, the increased infrastructure capacity often results in further increase of traffic flow which causes additional requirements for the capacity increase. Particularly in the urban areas, possibilities for increasing the infrastructure capacity are limited. Measures aimed at vehicles improve technical equipment which increase safety of vehicles for passengers as well as the surroundings of vehicles (e.g. ABS components, airbags, and crumple zones of vehicle). By improving technical equipment of vehicles, however, drivers drive more risky because they rely on this equipment. The smallest share of attention is currently devoted to the third factor which is driver behaviour. Various courses on road safety are recently organized but public authorities try to control the compliance with safe driving only by direct road checks. The aim of the paper is to point out that the positive effect on road safety can be achieved through significant support of bus service. The authors of the paper try to prove the hypothesis that the support of bus service has a multiplier effect which is reflected in the change of all three groups of the factors affecting road safety.

\section{Factors affecting the road safety}

Road safety is affected by many factors. According to Evans [6], Elvik et al. [7] or Hakkert and Gitelman [8], the most important factors are: driver's behaviour, vehicle construction and infrastructure conditions. Based on the analysis of existing scientific outputs, individual elements of those important factors affecting road safety are defined in Fig. 1.

Based on the extensive analysis, Evans [6] states that all factors are important but the driver behaviour seems to be the most important factor with the gradual construction of motorways and highways.

\section{Change in the quality of traffic infrastructure}

Traffic engineering and operating characteristics of the road network provide the background for increase of road safety [9].

\footnotetext{
* ${ }^{1}$ Milos Poliak, ${ }^{1}$ Lenka Komackova, ${ }^{1}$ Stefania Semanova, ${ }^{2}$ Salvador Hernandez, ${ }^{3}$ Marek Jaskiewicz

${ }^{1}$ Department of Road and Urban Transport, Faculty of Operation and Economics of Transport and Communications, University of Zilina, Slovakia ${ }^{2}$ School of Civil and Construction Engineering, Oregon State University, Corvallis, Oregon, USA

${ }^{3}$ Department of Automotive Vehicles and Transportation, Faculty of Mechatronics and Machine Engineering, Kielce University of Technology, Poland E-mail: milos.poliak@fpedas.uniza.sk
} 


\begin{tabular}{|l|l|l|}
\hline Infrastructure & Vehicle & Driver \\
Speed limits & Structure (aggressive/protective) & Physical/congnitive impairment \\
Congestion & Mass & Fatigue \\
Traffic segregation/integration & Power & Drugs and medicines \\
Traffic calming & Conspicuity & Alcohol \\
Readability of the road & ABS & Risk taking (speed) \\
Fixed obstacles & & Seat belt wearing (front/rear) \\
& & Children seats use \\
\hline
\end{tabular}

Fig. 1 Factors affecting road safety [Source: authors]

Elvik et al. classify traffic engineering safety initiatives in terms of road design, road maintenance, and traffic control. They find that in a global review of road engineering practices, the best safety benefit/cost investments come from separation of traffic (both direction and by vehicle type); from improved intersection design and control (left turn lanes, channelization, roundabouts at selected locations), black spot control and improvements, and improved signalling. Road maintenance practices have been found to have much lower safety impacts; the biggest safety benefits appear to be from increasing road friction and from good winter maintenance in terms of ice and snow control [7].

\section{Vehicle safety}

Vehicle design and performance attributes have two potential effects on safety: first, those aimed at reducing the risk of crashing; second, those aimed at reducing the consequences when accidents do occur.

Vehicle mass, size and speed have long been important concerns for manufacturers and for safety analysts. When accidents occur, vehicle mass and speed are two most important aspects determining accident severity and risk. Fatality risk depends strongly on the ratio of the masses of the vehicles; if one car is half as heavy as the other, the driver in the lighter car has approximately twelve times the fatality risk [10].

Accidents by nature involve rapid reduction in speed, and because vehicle occupants continue to move at the prior speed, occupancy protection devices are intended to reduce the likelihood and severity of collision. Both the integrated seat belt and shoulder harness, and even the basic safety belt, have been shown to be associated with major reductions in fatality risk [11]. In addition, airbags have been shown to be most effective when used in conjunction with seat belts.

\section{Driver behaviour}

Driver performance and driver behaviour are the biggest challenge in improving road safety [12]. Research literature finds strong safety effects for the increased use of seat belts, and control of speed. Driver education has little impact on safety [6]. Better knowing and increased enforcement of drunk driving laws has improved safety [13]. As Evans [6] notes, "The basic skills to stop, start, and steer vehicles are acquired remarkably easily and quickly. Complex higher level skills that are acquired only after many years of experience can contribute to reducing crash risk."

Based on the analysis of factors affecting road safety it is necessary to aim at the driver, driver's behaviour and skills.

The driving while intoxicated and effective control of alcohol use before driving have important role within driver's behaviour.

Ramsted [13] demonstrates that there is a correlation between the overall alcohol consumption in countries or provinces and fatal accidents rates. Yet, this correlation varies between different regions of the world and between the genders and age groups. An increase of 11 of pure alcohol per inhabitant of 15 years and above increases motor vehicle fatalities per 100000 inhabitants for men by 0.05 in Northern Europe; 2.1 in Central Europe and 0.8 in Southern Europe, by 3.2 in the US, and 3.6 in Canada. For women, the increase in motor vehicle fatalities is generally smaller than for men. Sheehan [14] demonstrates parallel trends for alcohol consumption and percentage of fatally injured drivers and motorcycle riders with BAC of $0.5 \mathrm{~g} / 1$ or greater for Queensland, Australia for 1982 - 2005.

The research states, that in traffic, it is possible to check a very small part of drivers despite of the fact that driving while intoxicated increases the risk of an accident. It is possible to check drivers of public passenger transport before starting working shift so increasing the share of those drivers can reduce the SPI level of driving while intoxicated.

\section{Multiplier effect of support of bus service on the road safety increase}

Within the support of public passenger transport it is possible to achieve change across all of the significant factors affecting the safety of road transport. Provided we proceed from the individual groups of factors and we assume that will not change the intensity of traffic flow (which implies the number of realized paths of 
the population), but it will increase the proportion of passengers using public transport, then it is possible for the support of public passenger transport, expect a multiplying effect on road safety.

By supporting bus service and transferring passengers to bus service, the density of traffic flow, which is expressed in number of vehicles per one kilometre of infrastructure, reduces [15]. We assume that the support of bus service decreases the density of traffic flow from $H_{A}$ to $H_{B}$ (see Fig. 2). The intensity of traffic flow is a function of the density that is:

$M=f(H)$

By changing the density of traffic flow it is possible to decrease the intensity of traffic flow:

\section{$\Delta \mathrm{M}=\mathrm{f}(\mathrm{HA}-\mathrm{HB}) ;$ under condition $\mathrm{HA} \leq \mathrm{Hopt}$}

In case that $\mathrm{H}_{\mathrm{A}}>\mathrm{H}_{\mathrm{opt}}$, congestions arise on infrastructure. By transferring passengers to the public transport, decrease in the density of traffic flow would release congestions and the intensity of traffic flow would increase. Figure 1 depicts the state of change in the density of traffic flow from $\mathrm{H}_{\mathrm{A}}{ }_{\mathrm{A}}$ to $\mathrm{H}_{\mathrm{B}}{ }_{\mathrm{B}}$. The figure also depicts speed $\mathrm{S}_{\mathrm{opt}}$ which can be achieved at maximum intensity of traffic flow. Exceeding this intensity, the speed of traffic flow decreases. Therefore, zero speed and zero intensity of traffic flow is achieved at maximum density of traffic flow $\left(\mathrm{H}_{\max }\right)$.

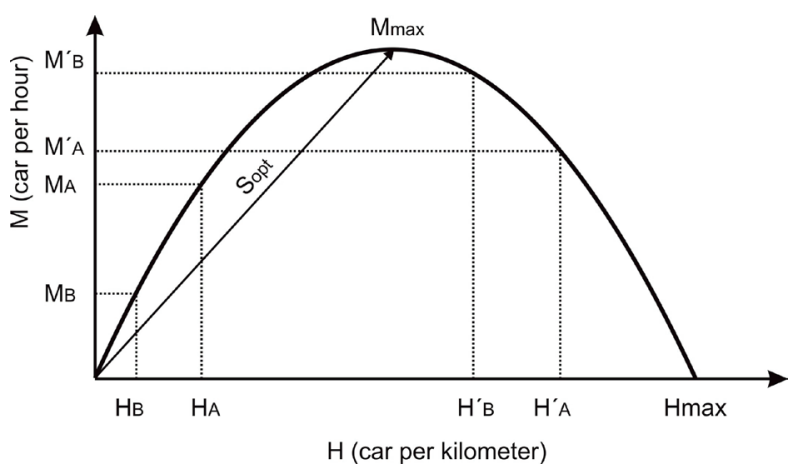

Fig. 2 Change of traffic flow intensity while changing the density of traffic flow under the support of bus service

[Source: authors based on [1]]

Yannis, G. et al. [1] defined the relationship between the probability of an accident and the intensity of traffic flow. Yannis, G. et al. characterized the likelihood of an accident as a function of the intensity of traffic flow where a course of the function is dependent on the category of the road network. Courses of dependence are shown in Fig. 3. The figure includes four categories of roads (R1 - the lowest category, R4 - the highest category). The following relationship can be stated for a particular category of roads: $r e=f(M)$

Let us assume that a particular road of R1 category has the intensity of traffic flow - $\mathrm{M}_{\mathrm{A}}$ and the probability of an accident $\mathrm{r}_{\mathrm{elA}}$ which exceeds the acceptable value of the accident probability - $r_{\text {eacc }}$. In practice, such a road is usually adjusted to a higher category - R2 which leads to decreasing the accident probability from $r_{\mathrm{e} 1 \mathrm{~A}}$ to $\mathrm{r}_{\mathrm{e} 2 \mathrm{~A}}$. However, within urban areas, this solution is not always possible and so the decrease of accident probability can be also achieved by decreasing the intensity of traffic flow from $\mathrm{M}_{\mathrm{A}}$ to $\mathrm{M}_{\mathrm{B}}$.

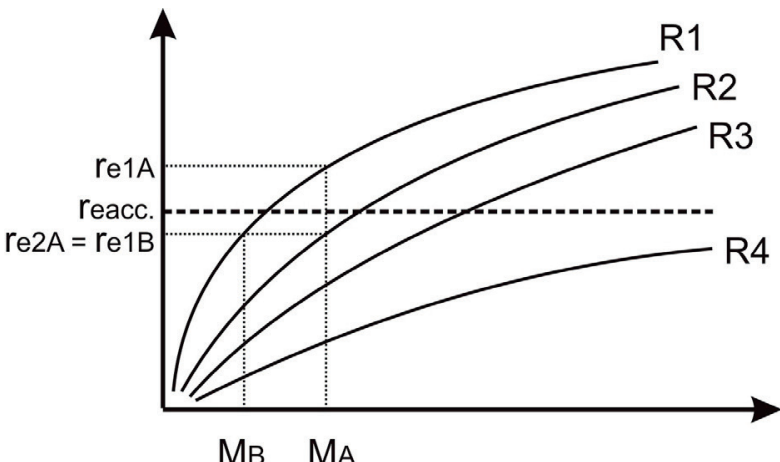

Fig. 3 Relationship between the accident probability and the intensity of traffic flow [Source: authors based on [1]]

This means that the result of the support of public passenger transport, through which the density of traffic flow would be decreased, can be expected in reduction of the risk of an accident, because the following applies:

$\Delta r e=f(M A-M B)=f(\Delta M)$

under condition $\mathrm{H}_{\mathrm{A}} \leq \mathrm{H}_{\mathrm{opt}}$, further applies

$\Delta \mathrm{re}=\mathrm{f}(\mathrm{f}(\mathrm{HA}-\mathrm{HB}))$

Based on above equation, it can be concluded that the density of traffic flow decreases through the support of bus service. The reason is that there are less transport means on roads which results in increasing road safety.

While increasing the safety of road transport in the current period, most options are in the change of accident rates, in particular in connection with the driver. In supporting public passenger transport, the proportion of drivers of bus transport would increase in the total number of drivers who lead vehicles in respect of the carriage of the passenger. To an increase in the share of buses would improve the value of the following factors:

- The physical condition of the driver - the drivers of the bus have set out the conditions for the implementation of travel (e.g. Regulation (EC) No 561/2006) according to which, after 
a specified time of driving the driver must draw the rest. For passenger vehicles, the driver is not limited to the time of driving, which for long driving affects the reaction times of the driver and increases the likelihood of a car accident [16].

- Psychological condition of the driver - the drivers of the bus attend regular psychological checks. Given that the driver of a passenger vehicle after the issuance of a driving licence does not have to go through such checks, it is possible to assume that the drivers of the bus are in a better mental condition.

- Use of drugs, drugs and alcohol - the drivers of the bus at the beginning of their working shift are checked regularly or randomly on the ingestion of alcohol or other narcotic substances. The driver is also under the control of the driving of the vehicle through the online equipment of the vehicle or even the camera. Therefore, it is significantly less likely that drivers will drive under the influence of alcohol [17].

- Risky driving - the drivers of the bus are drivers, who have higher experience with the management of vehicles and are able to better respond in risky situations. The drivers of the buses are regularly trained on the way of safe driving with your vehicle, therefore it can be assumed that the technique of driving the driver is safer when compared to the average technique driving other drivers. In the case of a risky ride it is possible to expect the reaction of the passengers [18 and 19]. The mentioned statement may be verified by testing individual groups of drivers. To obtain reliable results, it would be necessary to test a large number of drivers. The assumption that the bus drivers are safer drivers can be confirmed based on the statistical data relating to the number of accidents from the years of 2012 and 2013. Table 1 contains an overview of the number of road accidents separately for drivers of passenger cars and drivers of buses. Responsibility for the accident was not investigated; it was substantial that the driver was a participant of the accident. Furthermore, transfer performance expressed in passengerkilometre (pskm) was available for both transport modes over the period. The probability that a driver will be involved in an accident is necessary to calculate based on the number of road accidents and driving performance. However, Statistical Office of the SR does not measure and record driving performance for individual automobile transport. To determine the probability, the authors assume average utilization of buses at the level of 15 individuals (identified based on the Plan of transport serviceability in Zilina region - processing in 2008) and average utilization in individual automobile transport at the level of 1.5 individuals.

The average probability that a bus driver will be involved in an accident is at the level of 0.000000239 . The average probability that a driver of a passenger car will be involved in an accident is 0.000000417. Based on this analysis, it can be concluded that the probability that a bus driver will be involved in an accident is lower compared to a driver of a passenger car.
Comparison of road accidents separately for drivers of passenger cars and buses [authors based on [20]] Table 1

\begin{tabular}{|c|c|c|c|}
\hline $\begin{array}{l}\text { Transport } \\
\text { mode }\end{array}$ & Indicator & 2012 & 2013 \\
\hline \multirow[t]{4}{*}{ Bus service } & Number of accidents & 84 & 95 \\
\hline & $\begin{array}{l}\text { Transfer performance } \\
\text { (million pskm) }\end{array}$ & 5721 & 5533 \\
\hline & $\begin{array}{l}\text { Probability of an } \\
\text { accident }\end{array}$ & 0.00000022 & 0.00000026 \\
\hline & $\begin{array}{l}\text { Average probability of an } \\
\text { accident }\end{array}$ & \multicolumn{2}{|c|}{0.000000239} \\
\hline \multirow{4}{*}{$\begin{array}{l}\text { Individual } \\
\text { automobile } \\
\text { transport }\end{array}$} & Number of accidents & 7406 & 7640 \\
\hline & $\begin{array}{l}\text { Transfer performance } \\
\text { (million pskm) }\end{array}$ & 26935 & 27155 \\
\hline & $\begin{array}{l}\text { Probability of an } \\
\text { accident }\end{array}$ & 0.00000041 & 0.00000042 \\
\hline & $\begin{array}{l}\text { Average probability of an } \\
\text { accident }\end{array}$ & \multicolumn{2}{|c|}{0.000000417} \\
\hline
\end{tabular}

Based on the above mentioned, it is possible to verify the statement that the support of bus service has a multiplier effect on increasing road safety. On the one hand, it decreases the probability of a road accident through decreasing the intensity and density of traffic flow. On other hand, it increases the proportion of professional drivers whose probability to be involved in an accident is lower.

\section{Conclusion}

The aim of the paper was to prove the hypothesis that the support of bus service has a multiplier effect on increasing road safety. The paper confirms this hypothesis, and thus it can be stated that the support of bus service can significantly increase road safety. By increasing the number of individuals transported by public passenger transport, the multiplier effect of road safety increase can be achieved. The support of public passenger transport significantly decreases the risk of road accidents caused by drivers. Based on statistical findings, the probability of an accident caused by the professional drivers is lower by $42.7 \%$ compared to drivers of passenger cars. In addition, the risk of an accident is also decreased due to the change in intensity of traffic flow.

\section{Acknowledgement}

This paper was developed under the support of project: MSVVS SR - VEGA No. 1/0320/14 POLIAK, M.: Zvysovanie bezpecnosti cestnej dopravy prostrednictvom podpory hromadnej prepravy cestujucich. 


\section{References}

[1] YANNIS, G. et al: Road Safety Performance Indicators for the Interurban Road Network, Accident Analysis and Prevention, 60, 2013, 384-395; Elsevier 2013.

[2] IRTAD Annual Report @ OECD/ITF 2014.

[3] KOORNSTRA, M., LYNAM, D., NILlson, G., NOORDZIJ, P., PETTERSSON, H.-E., WEGMAN, F., WOUTERS, P.: SUNflower: A Comparative Study of the Development of Road Safety in Sweden, the United Kingdom, and the Netherlands. SWOV: Leidschendam, 2002.

[4] SUBRAMANIAN, R.: Motor Vehicle Traffic Crashes as a Leading Cause of Death in the United States, 2007. Traffic Safety Facts, Research Note. National Highway Traffic safety Administration, U. S. Department of Transportation, March 2011, DOT HS 811443.

[5] White Paper of the EU - Roadmap to a Single European Transport Area - Towards a competitive and resource efficient transport system (in Slovak), 2011.

[6] Evans, I.: Traffic Safety. Bloomfield Hills, MI: Science Serving Society, 2004.

[7] ELVIK, R. et al.: The Handbook of Road Safety Measures, $2^{\text {nd }}$ ed., Bingley : Emerald Group Publishing, 2009.

[8] HAKKERT, A. S., GITElmAN, V., VIS, M. A.: Road Safety Performance Indicators: Theory. Deliverable D3. 6 of the EU FP6 project SafetyNet, (Eds.), 2007.

[9] AASHTO: Highway Safety Manual. Washington: AASHTO, 2010.

[10] DAVIS, G. A.: Accident Reduction Factors and Casual Inference in Traffic Safety Studies, A Review, Accident Analysis and Prevention, 32(1), 95-109, 2000.

[11] COHEN, A., EVANS, L.: The Effects of Mandatory Seat Belt Laws on Driving Behaviour and Traffic Fatalities. Review of Economics and Statistics, 85 (4), 828-843. National Highway Traffic Safety Administration (December 2000). Fatality reduction by safety belts for front-seat occupants of cars and light trucks. Report DOT-HS-809-199. Washington: NHTSA. National Highway Traffic Safety Administration (2010a). Lives saved in 2009 by restraint use and minimum-drinking-age laws. Washington (DC): NHTSA, November 2003.

[12] SHINAR, D.: Traffic Safety and Human Behaviour, Bingley: Emerald Group Publishing, 2007.

[13] RAMSTEDT, M.: Alcohol and Fatal Accidents in the United States - A Time Series Analysis for 1950-2002. Accident Anal. Prev. 40, 1273.128; Skog, O. J., 2001. Alcohol consumption and mortality rates from traffic accidents, accidental falls, and other accidents in 14 European countries. Addiction, 96, 49-58. 2008.

[14] SHEEHAN, M.: Impaired Driving. Road Safety Summit. http://www.transport.qld.gov.au/Home/Safety/Road/Rs summit, 2006.

[15] POLIAK, M., KONECNY, V.: Factors Determining the Scope of Road Infrastructure Charged by Electronic Toll (in Slovak), Ekonomicky casopis = J. of Economics. ISSN 0013-3035, vol. 56, No. 7, 2008, 712-731.

[16] JELINEK, J.: Municipal Public Transport Line Modelling, Communications - Scientific Letters of the University of Zilina, No. 2, 2014, pp. 4-8.

[17] KAlasova, A., CERNICKY, L., KUBIKOVA, S.: Microscopic Simulation of Coordinated Route in the City of Zilina. Communications - Scientific Letters of the University of Zilina, No. 2, 2014, pp. 46-50.

[18] NEDELIAKOVA, E., NEDELIAK, I.: Quality Level of an Integrated Transport System in the Context of Information and Communication Technologies. Transport \& Logistics [elektronicky zdroj] = Doprava a logistika. ISSN 1451-107X. vol. 13, No. 282013.

[19] POLIAKOVA, A.: Customer Satisfaction Index with a Quality of Service in Public Mass Transport. Doprava a spoje [elektronicky zdroj] : internetovy casopis. ISSN 1336-7676. No. 2, 2010, 43-49.

[20] Statistical Office of the Slovak Republic. 